\title{
Correction: Image guided dose escalated prostate radiotherapy: still room to improve
}

\author{
Jarad M Martin ${ }^{1,2}$, Andrew Bayley ${ }^{1}$, Robert Bristow ${ }^{1}$, Peter Chung ${ }^{1}$, \\ Mary Gospodarowicz ${ }^{1}$, Cynthia Menard ${ }^{1}$, Michael Milosevic ${ }^{1}$, Tara Rosewall ${ }^{1}$, \\ Padraig R Warde ${ }^{1}$ and Charles N Catton*1
}

\begin{abstract}
Address: ${ }^{1}$ Princess Margaret Hospital, Department of Radiation Oncology, Princess Margaret Hospital, University of Toronto, Toronto, Ontario, Canada and ${ }^{2}$ Cancer Care Services, Royal Brisbane and Women's Hospital, Herston, Queensland, Australia

Email: Jarad M Martin - jarad.martin@roq.net.au; Andrew Bayley - Andrew.Bayley@rmp.uhn.on.ca; Robert Bristow - Robert.Bristow@rmp.uhn.on.ca; Peter Chung - Peter.Chung@rmp.uhn.on.ca; Mary Gospodarowicz - Mary.Gospodarowicz@rmp.uhn.on.ca; Cynthia Menard - Cynthia.Menard@rmp.uhn.on.ca; Michael Milosevic - Michael.Milosevic@rmp.uhn.on.ca; Tara Rosewall - Tara.Rosewall@rmp.uhn.on.ca; Padraig R Warde - Padraig.Warde@rmp.uhn.on.ca; Charles N Catton* - Charles.Catton@rmp.uhn.on.ca

* Corresponding author
\end{abstract}

Published: 16 December 2009

Radiation Oncology 2009, 4:65 doi:10.1186/1748-717X-4-65

This article is available from: http://www.ro-journal.com/content/4/I/65

(C) 2009 Martin et al; licensee BioMed Central Ltd.

This is an Open Access article distributed under the terms of the Creative Commons Attribution License (http://creativecommons.org/licenses/by/2.0), which permits unrestricted use, distribution, and reproduction in any medium, provided the original work is properly cited.

\section{Abstract}

We regret to report that a proofreading error caused an incorrect legend and description of the contents of table 6 to appear in our original publication of this work. The correct description of table 6 is: Univariate analysis of prognostic factors for 5 -year nadir +2 biochemical outcome for men presenting with intermediate risk factors.

\section{Correction}

We regret to report that a proofreading error caused an incorrect legend and description of the contents of table 6 to appear in our original publication of this work [1]. The correct description of table 6 is: Univariate analysis of prognostic factors for 5-year nadir +2 biochemical outcome for men presenting with intermediate risk factors.

\section{References}

I. Martin J, Bayley A, Bristow R, Chung P, Gospodarowicz M, Ménard C, Milosevic M, Rosewall T, Warde P, Catton C: Image guided dose escalated prostate radiotherapy: still room to improve. Radiation Oncology 2009, 4:50. 